\title{
BMJ Open Characteristics of medical disputes arising from dental practice in Guangzhou, China: an observational study
}

\author{
Zifeng Liu, ${ }^{1,2}$ Yong Zhang, ${ }^{3}$ Joseph Obiri Asante, ${ }^{3}$ Yixiang Huang, ${ }^{3}$ Xin Wang, ${ }^{3}$ \\ Lijin Chen ${ }^{3}$
}

To cite: Liu Z, Zhang Y, Asante J0, et al. Characteristics of medical disputes arising from dental practice in Guangzhou, China: an observational study. BMJ Open 2018;8:e018738. doi:10.1136/ bmjopen-2017-018738

- Prepublication history for this paper is available online. To view these files, please visit the journal online (http://dx.doi. org/10.1136/bmjopen-2017018738).

$\mathrm{ZL}$ and $\mathrm{YZ}$ contributed equally.

Received 18 July 2017 Revised 15 November 2017 Accepted 8 December 2017

Check for updates

${ }^{1}$ Guanghua School of Stomatology, Hospital of Stomatology, Sun Yat-sen University, Guangzhou, Guangdong, China

${ }^{2}$ Guangdong Provincial Key Laboratory of Stomatology, Sun Yet-sen University, Guangzhou, Guangdong, China

${ }^{3}$ School of Public Health, Sun Yat-sen University, Guangzhou, Guangdong, China

Correspondence to Dr Yixiang Huang; huangyx@mail.sysu.edu.cn

\section{ABSTRACT}

Objectives Doctor-patient conflict is a phenomenon that has become one of the major social problems affecting China's medical system today. This study aimed to analyse the nature of medical dispute incidents arising from dental practice, discover the related factors that may have incited such disputes and explore measures whereby the incidents of patients' conflicts towards dentists can be reduced.

Methods A survey conducted in six public hospitals in Guangzhou, one of the largest cities in China, showed that more than two million patients received dental treatment between 2008 and 2012. $\chi^{2}$ test and binary logistic regression analysis were used to identify statistically significant differences in incident rates.

Results In a total of more than two million outpatients, 541 reported dental disputes and lodged complaints with the medical service centre. Male patients reported higher dispute rates than did females $\left(\chi^{2}=9.74, P<0.01\right)$. Binary logistic regression analysis further showed that disputes developed into conflicts depending on five factors: patient gender, dental specialty, cause of dispute, mode of payment and resolution duration.

Conclusions Gender, specialties, cause of dispute, mode of payment and resolution duration are associated with the incidence of dental conflicts, suggesting that medical quality is positively correlated to dental disputes, the coverage of stomatology in medical insurance should be expanded and detailed negotiation system should be developed for resolving dental disputes.

\section{INTRODUCTION}

The level of violence against medical professionals in China is on the rise compared with that in other countries ${ }^{1}$ and is becoming more alarming by the day. In 2011, a survey conducted in 10 provinces in China showed that $3.4 \%$ of physicians had been physically assaulted by their patients or patients' relatives in the preceding 12 months. $^{2}$ Similar incidents have also occurred in dentistry. On 5 May 2016, a retired dentist in Guangdong General Hospital was stabbed by a former patient and died 2 days later. ${ }^{3}$ This
Strengths and limitations of this study

- Our study is the first to focus on dental disputes in China, specifically Guangzhou, to aid in the detailed analysis of the characteristics of such disputes.

- Unbiased and reliable data on dental disputes were gathered from six hospitals in Guangzhou city.

- The $\nabla^{2}$ test and binary logistic regression analysis were used to analyse the data to elucidate the nature of dental disputes.

- The study also provides guidelines and measures to prevent dental disputes, dental malpractice and violence towards dentists in China.

- The limitation of this study is that data were gathered from only six hospitals in Guangzhou, so the results cannot be generalised to the entire country.

frightening situation is having negative effects on the next generation of doctors. According to the Chinese Medical Doctors' Association, in 2011, only $7 \%$ of doctors recommended that their children attend medical colleges. ${ }^{4}$ Consequently, studies on dental violence are urgently needed to address this menace.

Violence against medical professionals has existed in China for quite some time. ${ }^{5-7}$ This problem is a global phenomenon, with various degrees of severity in different countries. ${ }^{89}$ For example, in the USA, approximately $3 \%-4 \%$ of all doctors in different fields reported complaints in 1970, with the number increasing to $20 \%$ in 1980 and $25 \%$ in $1990 .^{10}$

Conflicts between patients and physicians are more serious in China, leading to verbal abuses, threats and various degrees of physical assaults. According to data from 2002 to 2012, medical conflicts in China grew 10\% annually, and more than $60 \%$ of hospitals experienced such violence. ${ }^{11}$ Accordingly, in 2015, the Chinese government amended the criminal law, which stipulates that any person 


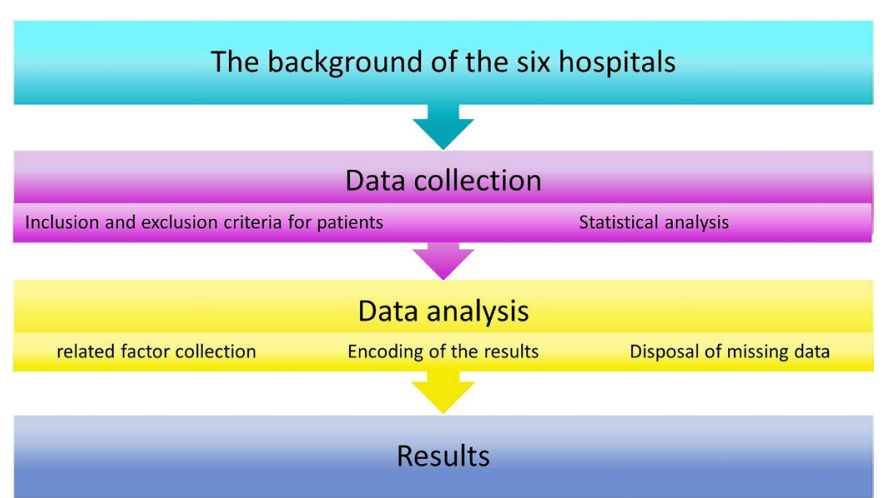

Figure 1 Flow chart of the collection, organisation and analysis of data.

involved in violence towards medical professionals or mobs, called yinao, shall bear the corresponding criminal responsibility. Previous research studies have suggested that medical malpractice, patient-physician mistrust, information irregularity and high out-of-pocket expense might lead to patient-physician conflicts. ${ }^{12}$ What is more, the lack of a caregiving spirit on the part of physicians exacerbates the mistrust. ${ }^{13}$ However, there has been little quantitative research on the impact of risk/protective factors on violence against medical professionals in China.

A dental dispute is a type of medical dispute and arises because of different views expressed by dentists and their patients, resulting in adverse consequences and legal liability. In recent times, dentistry has seen increased numbers of patients, more traumatised patients, uncomfortable dental procedures and more 'self-pay' procedures resulting in medical disputes. One study showed that dentistry ranks among the medical disciplines faced with the most frequent medical malpractice claims in Germany. ${ }^{14}$ However, there are no data on malpractice claims against dentists in China.

In an attempt to understand the nature of disputes arising from dental practice, we defined 'dental disputes' as conflicts between a dentist and his/her patient, whereby the patient appears to be emotionally agitated, abusive, issuing threats and displaying violence during the complaints. We conducted this study in Guangzhou, the largest city in South China, with a population of

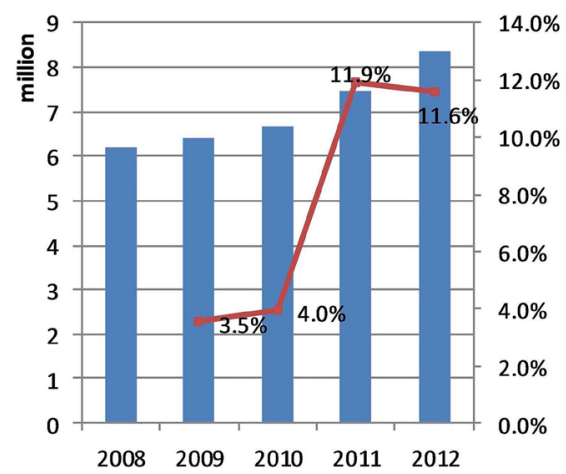

Figure 2 Number of patients with oral diseases and growth rate thereof.

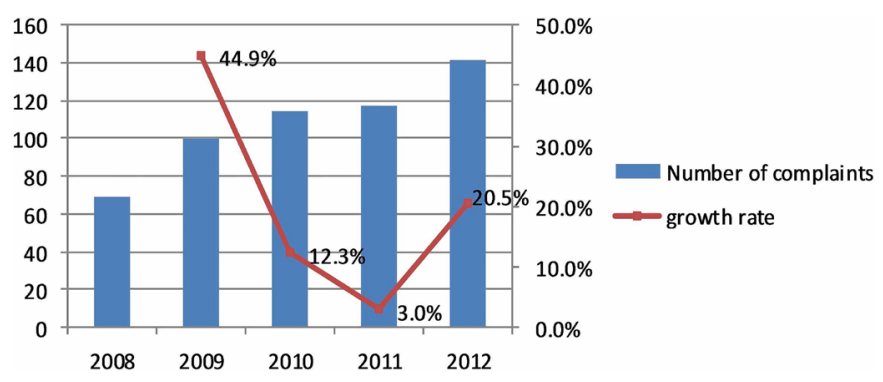

Figure 3 Number of complaints and growth rate.

14 million, to identify whether gender, specialties, cause of dispute, mode of payment and other various factors are related to these dental conflicts. The aim of this study was to achieve a better understanding of dental conflicts, and to offer a foundation for the implementation of longterm preventive strategies.

\section{MATERIALS AND METHODS}

\section{Data collection}

The target population of the study included most of outpatients receiving dental treatment from 2008 to 2012 at six public hospitals in Guangzhou city, China. They all have stomatology specialties.

For our study, we were permitted to access the database of those six hospitals from the hospital information system. All the information we gathered had patient consent, and there was no identifying patient information, thus protecting patient privacy.

During this period, we first got in touch with the medical service centre, and then input the data from the six hospitals. Second, the dental patients who complained to the dentists or the hospital and had registered were included. To complete the complaint process, the patient must visit the medical service centre and fill out a form including the name, sex, department in which the complaint was being lodged, the reason for the complaint and the expectation of outcome; this constituted the original information. As such, information was self-reported by the patient, and its reliability and accuracy were confirmed by the patient's signature collected at the bottom of the form. After that, all the information was input into the computer. The complaints unrelated to stomatology were excluded from this study. Third, all dental dispute cases included were subjected to statistical analysis.

\section{Analysis}

Factors such as patient's gender, age, dental specialties, reason for dispute, resolution methods, resolution duration, payment type, doctor's rank and the year of dispute occurrence, collected from the registered information, were selected for further analysis to determine their association with dental disputes.

The results were then divided into two parts, according to the registration information, based on whether or not conflict. Disputes that led to conflicts were coded ' 1 ' and treatment results without conflicts were coded ' 2 '. 
Table 1 Characteristics of the dental dispute incidents

\begin{tabular}{|c|c|c|c|c|}
\hline & Conflict, n=79 (\%) & Without conflict, $n=462(\%)$ & OR & $P$ value \\
\hline Years & & & & 0.067 \\
\hline 2008 & $12(2.2)$ & $57(10.5)$ & 1 & \\
\hline 2010 & $17(3.1)$ & $97(17.9)$ & 1.34 & 0.43 \\
\hline 2011 & $16(3.0)$ & $101(18.7)$ & 0.90 & 0.79 \\
\hline Dental specialties & & & & $<0.05$ \\
\hline Endodontics & $15(2.8)$ & $138(25.5)$ & 1 & \\
\hline Prosthodontics & $10(1.8)$ & $99(18.3)$ & 0.92 & 0.86 \\
\hline Oral and maxillofacial surgery & $18(3.3)$ & $57(10.5)$ & 2.91 & $<0.01$ \\
\hline Dispute reason & & & & $<0.01$ \\
\hline Medical quality & $45(8.3)$ & $174(32.2)$ & 1 & \\
\hline Informed consent & $7(1.3)$ & $106(19.6)$ & 0.26 & $<0.01$ \\
\hline Medical expenses & $3(0.5)$ & $24(4.4)$ & 0.48 & 0.25 \\
\hline Hospital management & $24(4.4)$ & $158(29.2)$ & 0.59 & 0.06 \\
\hline Resolution methods & & & & $<0.01$ \\
\hline Negotiation & $74(13.7)$ & $457(84.5)$ & 1 & \\
\hline Litigation & $5(0.9)$ & $5(0.9)$ & 6.18 & $<0.01$ \\
\hline Patient gender & & & & $<0.01$ \\
\hline Medical insurance & $16(3.0)$ & $142(26.2)$ & 0.52 & $<0.05$ \\
\hline Doctor title & & & & 0.71 \\
\hline Senior title & $21(3.9)$ & $127(23.7)$ & 1 & \\
\hline Intermediate title & $26(4.8)$ & $169(31.2)$ & 0.93 & 0.82 \\
\hline Junior title & $32(5.9)$ & $165(30.5)$ & 1.17 & 0.60 \\
\hline
\end{tabular}

A professional organisation called the Medical Mediation Committee, consisting of doctors and lawyers who form an expert panel on dental claims, judged the complaints. The expert panel awarded compensations for dental disputes, and compensations were paid by hospitals or medical insurance. Dental dispute data were input into study database. Data were analysed by using SPSS V.20 software. We conducted the $\chi^{2}$ test and binary logistic regression analysis to identify statistically significant differences in incident rates. First, the $\chi^{2}$ test was conducted to determine if the factors such as patient gender, age, dental specialties, reason for dispute, resolution methods, resolution duration, payment type, doctor's rank and the year of dispute occurrence were statistically associated with medical disputes. An OR was calculated for dental disputes that resulted in conflicts and disputes without conflicts. Subsequently, binary logistic regression analysis was used to determine whether the above-mentioned independent variables could lead to medical conflicts. Statistical significance was defined as $\mathrm{P}<0.05$.

\section{Supplements to missing data}

Missing item values from individual surveys were imputed with the mean value. During our research, we found that, in about 500 cases, only five individuals received compensation. Therefore, we ignored the compensation factor in our analysis, based on limited data. The methods described above are explained in a flow chart form in figure 1 . 


\begin{tabular}{|c|c|c|}
\hline Variable & $\begin{array}{l}\text { Adjusted } \\
\text { OR }(95 \% \mathrm{Cl})\end{array}$ & $P$ value \\
\hline Patient gender & & $<0.01$ \\
\hline Female & 1 & \\
\hline Male & 2.96 (1.70 to 5.16$)$ & \\
\hline Dental specialties & & $<0.01$ \\
\hline Endodontics & 1 & \\
\hline Prosthodontics & 1.00 (0.38 to 2.55$)$ & 0.98 \\
\hline $\begin{array}{l}\text { Oral and maxillofacial } \\
\text { surgery }\end{array}$ & 3.19 (1.36 to 7.47$)$ & $<0.01$ \\
\hline Orthodontics & $3.40(1.00$ to 11.56$)$ & 0.05 \\
\hline $\begin{array}{l}\text { Periodontology and } \\
\text { oral mucosa }\end{array}$ & 3.55 (1.43 to 8.79$)$ & $<0.01$ \\
\hline Administration office & 3.56 (1.38 to 9.19$)$ & $<0.01$ \\
\hline Dispute reason & & $<0.01$ \\
\hline Medical quality & 1 & \\
\hline Informed consent & 0.24 (0.09 to 0.57 ) & $<0.01$ \\
\hline Medical expenses & $0.45(0.12$ to 1.75$)$ & 0.25 \\
\hline Hospital management & $0.47(0.22$ to 0.97$)$ & $<0.05$ \\
\hline Payment type & & $<0.01$ \\
\hline Self-paying & 1 & \\
\hline Free medical service & 0.30 (0.13 to 0.66$)$ & $<0.01$ \\
\hline Medical insurance & 0.38 (0.20 to 0.71$)$ & $<0.01$ \\
\hline Solution days & 1.01 (1.00 to 1.01$)$ & $<0.01$ \\
\hline
\end{tabular}

\section{RESULTS}

The numbers of outpatients with oral diseases and dental dispute incidents

According to The Health Statistics Almanac from 2008 to 2012, the number of outpatients with oral diseases is growing annually in Guangdong province, with growth rates of more than $10 \%$ in 2011 and 2012 (figure 2).
According to our survey data, the number of complaints also showed an annual upward trend, with data in 2009 being the highest, $44.9 \%$ (figure 3), but the trends of both growth rates were not consistent. In 2011, the growth rate for outpatients reached the highest peak $(11.9 \%)$, while the growth rate for complaints was only $3.0 \%$, which was the lowest value recorded within the 5 -year period.

\section{The characteristics of the dental dispute incidents}

The nature of the 541 medical complaint incidents arising from dental practice is listed in table 1. About $15 \%$ of the dental complaints resulted in conflict. In general, the $\chi^{2}$ test showed that male patients, dental specialties such as oral and maxillofacial surgery, periodontology and oral mucosa, medical quality and self-paying patients $(\mathrm{P}<0.05)$ were highly associated with dental disputes.

In total, male patients recorded more complaints than did female patients $\left(\chi^{2}=5.955, \mathrm{P}=0.015\right)$.

Annual dispute rates differed, but not statistically significantly $(\mathrm{P}>0.05)$. The endodontic and prosthodontic specialties received more complaints than other dental specialties regardless of conflict. The reason behind most disputes was medical quality. The major method for resolving dental disputes was through negotiation. Self-paying disputes constituted a higher proportion of payment type among all the disputes.

\section{Factors related to conflicts}

Table 2 shows the outcome of the binary logistic regression analysis. The dependent variable is whether physical conflicts occur or not during dental disputes, and the independent variables are patient gender, dental specialties, dispute reason, payment type and resolution time. The results indicated that all of these factors have statistical correlation with physical conflicts. Male complaints (OR 2.96, 95\% CI 1.70 to 5.16) tended to involve more physical conflict during the process of dental disputes. Compared with the endodontic department, the departments of oral and maxillofacial

1. The number of outpatients with oral diseases and dental dispute incidents

- a growing trend in oral diseases

- an upward trend in complaints

2. The characteristics of the dental dispute incidents

- male patients, dental specialities such as oral and maxillofacial surgery, periodontology and oral mucosa, medical quality and self-paying patients are highly associated with medical conflicts

3. Factors related to conflicts

- patient gender, dental specialties, dispute reason, payment type and resolution time are correlated with conflicts

Figure 4 The main findings of this study. 
surgery (OR 3.05, 95\% CI 1.33 to 7.01), periodontology and oral mucosa (OR 3.19, 95\% CI 1.36 to 7.47 ) and the administration office (OR 3.56, 95\% CI 1.38 to 9.19) were more likely to have physical conflicts. It is interesting to note that informed consent (OR 0.24, 95\% CI 0.09 to 0.57 ) and hospital management (OR $0.47,95 \%$ CI 0.22 to 0.97 ) were less problematic than medical quality. In contrast to self-payments, complaints of free medical service (OR 0.30, 95\% CI 0.13 to 0.66 ) and medical insurance (OR $0.38,95 \%$ CI 0.20 to 0.71 ) were less likely to result in physical conflict. Finally, dispute resolution time (OR 1.01, 95\% CI 1.00 to 1.01 ) was a weak precursor of physical conflict.

The main findings of this study are listed in figure 4 .

\section{DISCUSSION}

In recent times, being a doctor in China has by no means been easy and, to some degree, has even been dangerous. A national survey indicated that the year 2006 saw 9831 disputes with 5519 injured medical personnel, and in the year 2007, $73.3 \%$ of the hospitals in mainland China reported violence. ${ }^{15}$ Liu et $a l^{16}$ conducted a survey among 11 tertiary hospitals in the urban area in Heilongjiang province of China. Their results showed that specialist hospitals had the highest prevalence of physical violence $(35.4 \%)$, while the general hospitals had the highest prevalence of non-physical violence $(76 \%)$. This study focused on violence towards dentists which is uncommon.

In this study, we analysed the demographics of dental patients, the characteristics of dental dispute incidents and the factors related to physical conflicts. Several findings are noteworthy.

The first is that medical quality was the reason most often cited for dental conflict. From table 1, it can be seen that poor medical quality (including insufficient communication, high expectations of dentists, complications and treatment failure) constituted $40 \%$ of the total dispute reasons, and it occurs to conflict more easily than other reasons. In other words, dental patients were dissatisfied with the outcome of the services at hospitals. The probable explanation for this is the gap between patients' expectation and therapeutic effects. Additionally, irreversible injuries such as gingival recession which is the displacement of the marginal gums away from the tooth by mechanical (such as brushing), chemical or surgical means ${ }^{17}$; mandibular fractures, typically as a result of trauma, ${ }^{18}$ and dental extraction, as a result of tooth decay, periodontal disease or dental trauma experienced by the patients during dental treatment exacerbate their dissatisfaction for dentists. Moreover, the high cost of follow-up treatments and limited coverage range of medical insurance result in higher self-paying cost. These reasons account for high proportion of dental disputes.

As mentioned earlier, medical quality is related to dental disputes, and medical malpractice is one of the most severe problems of medical quality. According to medical malpractice definition, ${ }^{19}$ dental malpractice can be defined as any act or omission by a dentist during treatment of a patient that deviates from the accepted norms of practice in the dental community and causes injury to the patient. Despite the significant progress in science and the new technologies available for the diagnosis and treatment of medical conditions, the rate of complaints due to medical malpractice shows an increasing trend. ${ }^{8}$ It is an underestimated global problem and calls for more attention into the investigation and handling of malpractice charges. ${ }^{80-23}$ A 5-year survey of dental malpractice claims in Iran showed that dentists were at fault in $56.7 \%$ of clinical cases and $40 \%$ of non-clinical cases. ${ }^{24}$

Malpractice claims may frequently occur in prosthodontics, as one of the specialties leading to the highest number of dental disputes. ${ }^{25}$ The reason for such a situation is due to the special treatment procedures in dentistry. A patient can easily feel the change in his/her body after a dentist administers treatment. It is, therefore, relatively easy for the patient to know the effect of treatment outcome. Therefore, patients may become disgruntled after treatment because of initially high expectations. Further, although the number of dentists has continued to grow since 1949, the ratio of registered dentists to the total population was still only 1:7560 in $2009 .{ }^{20}$ Therefore, an increase in population, as well as an increase in patients' medical knowledge and awareness of their rights, thanks largely to the internet, might be another reason for the increase in dental patient claims.

What is more, the proportion of complaints without conflict was more than $85 \%$, indicating that most disputes were resolved before conflict developed. The first reason for this is likely that, in most cases, dental illness does not seem serious or life-threatening. The second reason is that the cost of the procedure would not be excessive, and patient expectations would be lower than in other medical specialties.

In addition, 'self-paying' occupied a higher proportion of all payment types. Conflict occurs more easily with selfpaying patients. In contrast, free medical services report little conflict. People who receive free medical service are required to pay only $10 \%$ of the outpatient's bill. However, medical insurance does not cover many dental procedures, so patients must cover those costs themselves. The more costs they pay, the higher the expectations they have for the treatment. Thus, patients become more easily dissatisfied with the service they receive, which could result in medical complaints or disputes. Therefore, it is significant to expand stomatology coverage in medical insurance. Reducing self-paying costs in dental treatment is an effective way of limiting dental disputes.

The last problem relates to methods of resolution. Our findings showed that only $1.8 \%$ of complainants used the option of litigation to defend their legal rights. Nearly $98 \%$ opted for negotiation, in contrast to similar scenarios in foreign countries. A new study of dental treatment injuries claims in Finland demonstrated that $40 \%$ were eligible for reimbursement, $27 \%$ were classified as insignificant or unavoidable injuries and $32 \%$ were rejected for other reasons. ${ }^{26}$ In China, with litigation, it can take nearly 2 or 3 years for a dispute to 
be judged, which explains why almost $50 \%$ of complainants in China opt for negotiation but not litigation, suggested by a review during $2009-2013 .{ }^{27}$ Second, there are many institutions, including hospitals, medical mediation committees and courts, in which people can complain. Thus, fewer people choose litigation. Due to the advantages of neutrality, professionalisation and low cost, ${ }^{28}$ more and more complainants ask for negotiation. Improved mediation should be mentioned as the best avenue for a high proportion of those who have opted for negotiation to attain better solutions of medical disputes. Further, effective communication and informed consent, ${ }^{24}$ greater care and ethical professionalism may help dentists avoid medical disputes. ${ }^{25}$

A limitation of this study is that data collection took place in only six public hospitals in Guangzhou, and we analysed only 541 samples that included dental disputes. Although the total number of sampled respondents is sufficient for us to draw conclusions, we could have broadened our conclusions if we had more support and access to data in more cities in China.

\section{CONCLUSION}

We found that patient gender, dental specialties, cause of dispute, mode of payment and resolution duration are the primary risk factors for the medical conflicts. Medical quality is positively correlated to dental disputes. Therefore, improving medical quality and fine-tuning the mediation system to avoid disputes with conflict is essential to decreasing dental disputes. As self-payment is a risk factor, establishing an insurance policy that includes more stomatology insurance reimbursement items may help to minimise conflicts towards dentists.

Acknowledgements The authors thank the 541 patients who, according to the survey, experienced dental disputes. The authors also thank the six hospitals in Guangzhou city, China, for providing adequate information on medical disputes.

Contributors ZL and YH proposed the idea and designed the research. JOA, XW and $\mathrm{LC}$ developed the survey and collected the data. ZL, XW and LC were involved in data analysis and interpretation. ZL and YZ drafted the manuscript. YH and JOA reviewed the manuscript. All authors read and approved the final manuscript.

Funding This study was funded by the Guangdong Science and Technology Foundation for Social Science (grant/award number 2016A070705025).

Competing interests None declared.

Patient consent Detail has been removed from this case description/these case descriptions to ensure anonymity. The editors and reviewers have seen the detailed information available and are satisfied that the information backs up the case the authors are making.

Ethics approval This study was approved by the Medical Ethics Committee, School of Public Health, Sun Yat-sen University.

Provenance and peer review Not commissioned; externally peer reviewed.

Data sharing statement Data were acquired from all outpatients receiving dental treatment from 2008 to 2012 at six hospitals in Guangzhou city, China. No additional data are available.

Open Access This is an Open Access article distributed in accordance with the Creative Commons Attribution Non Commercial (CC BY-NC 4.0) license, which permits others to distribute, remix, adapt, build upon this work non-commercially, and license their derivative works on different terms, provided the original work is properly cited and the use is non-commercial. See: http://creativecommons.org/ licenses/by-nc/4.0/ (c) Article author(s) (or their employer(s) unless otherwise stated in the text of the article) 2018. All rights reserved. No commercial use is permitted unless otherwise expressly granted.

\section{REFERENCES}

1. Hesketh T, Wu D, Mao L, et al. Violence against doctors in China. BMJ 2012;345:e5730-1433.

2. Zhang $X$, Sleeboom-Faulkner M. Tensions between medical professionals and patients in mainland China. Camb Q Healthc Ethics 2011;20:458-65.

3. Chenxi L. People mourn doctor killed by former patient in Guangdong. 2016 http://english.cri.cn/12394/2016/05/08/ 4061s926921.htm

4. Association CMD. Fourth Chinese physician practice status of research reports. $2011 \mathrm{http}: / / w w w . c m d a . g o v . c n / g o n g z u o d o n g t a i /$ zhinengbumen/2011-08-08/9778.html

5. Anon. Ending violence against doctors in China. Lancet 2012;379:1764.

6. Li H, Wu X, Sun T, et al. Claims, liabilities, injures and compensation payments of medical malpractice litigation cases in China from 1998 to 2011. BMC Health Serv Res 2014;14:390.

7. Anon. Violence against doctors: why China? Why now? What next? Lancet 2014;383:1013.

8. Jena $A B$, Seabury $S$, Lakdawalla $D$, et al. Malpractice risk according to physician specialty. N Engl J Med 2011;365:629-36.

9. Osti M, Steyrer J. A national survey of defensive medicine among orthopaedic surgeons, trauma surgeons and radiologists in Austria: evaluation of prevalence and context. J Eval Clin Pract 2015;21:278-84.

10. Sox HC, Woloshin S. How many deaths are due to medical error? Getting the number right. Eff Clin Pract 2000;3:277-83.

11. Zhang J. Solve the institution without effective to trigger the emotiondealing with "Yinao" in different aspects. Public Management Newspaper 2017;14:61-73.

12. Lyu SY, Liao CK, Chang KP, et al. Analysis of medical litigation among patients with medical disputes in cosmetic surgery in Taiwan. Aesthetic Plast Surg 2011;35:764-72.

13. Tucker JD, Cheng Y, Wong B, et al. Patient-physician mistrust and violence against physicians in Guangdong Province, China: a qualitative study. BMJ Open 2015;5:e008221.

14. Knaak JP, Parzeller M. Court decisions on medical malpractice. Int $J$ Legal Med 2014;128:1049-57.

15. ZHANG H, ZHANG Y. An epidemic of violence on medical personnel: are we prepared. Journal of Medical Colleges of PLA 2013;28:120-4.

16. Liu $\mathrm{H}$, Zhao S, Jiao M, et al. Extent, Nature, and Risk Factors of Workplace Violence in Public Tertiary Hospitals in China: A CrossSectional Survey. Int J Environ Res Public Health 2015;12:6801-17.

17. Mondofacto medical dictionary. gingival retraction. $2000 \mathrm{http}: / / \mathrm{www}$. mondofacto.com/facts/dictionary?gingival-retraction

18. Murray JM. Mandible fractures and dental trauma. Emerg Med Clin North Am 2013;31:553-73.

19. Bal BS. An introduction to medical malpractice in the United States. Clin Orthop Relat Res 2009;467:339-47.

20. Santos P, Ritter GA, Hefele JL, et al. Decreasing intrapartum malpractice: Targeting the most injurious neonatal adverse events. $J$ Healthc Risk Manag 2015;34:20-7.

21. Jena $A B$, Schoemaker L, Bhattacharya J, et al. Physician spending and subsequent risk of malpractice claims: observational study. $B M J$ 2015;351:h5516.

22. Spittal MJ, Bismark MM, Studdert DM. The PRONE score: an algorithm for predicting doctors' risks of formal patient complaints using routinely collected administrative data. BMJ Qual Saf 2015;24:360-8.

23. Turillazzi E, Neri M. Informed consent and Italian physicians: change course or abandon ship - from formal authorization to a culture of sharing. Med Health Care Philos 2015;18:449-53.

24. Kiani M, Sheikhazadi A. A five-year survey for dental malpractice claims in Tehran, Iran. J Forensic Leg Med 2009;16:76-82.

25. Nassani MZ. Aspects of Malpractice in Prosthodontics. $J$ Prosthodont 2017;26:672-81.

26. Karhunen S, Virtanen JI. Dental treatment injuries in the Finnish Patient Insurance Centre in 2000-2011. Acta Odontol Scand 2016;74:236-40.

27. Zhang NL, Zhao J. Analysis about medical disputes cases during 2009 to 2013. Medicine and Society 2014:27.

28. Chang-chao L. Empirical research on the third-party mediation mechanism in medical dispute. The Chinese Health Service Management 2014;308:125-7. 